\title{
A Diagnosis of Rainfall over South America during the 1997/98 El Niño Event. Part I: Validation of NCEP-NCAR Reanalysis Rainfall Data
}

\author{
V. Brahmananda Rao, Clóvis E. Santo, and Sergio H. Franchito \\ Instituto Nacional de Pesquisas Espaciais, Sao Jose dos Campos, Sao Paulo, Brazil
}

(Manuscript received 7 December 2000, in final form 12 June 2001)

\begin{abstract}
A comparison between the National Centers for Environmental Predictions-National Center for Atmospheric Research (NCEP-NCAR) reanalysis rainfall data and the Agência Nacional de Energia Elétrica (ANEEL) rain gauge data over Brazil is made. It is found that over northeast Brazil, NCEP-NCAR rainfall is overestimated. But over south and southeast Brazil, the correlation between the two datasets is highly significant showing the utility of NCEP-NCAR rainfall data. Over other parts of Brazil the validity of NCEP-NCAR rainfall data is questionable. A detailed comparison between NCEP-NCAR rainfall data over northwest South America and rain gauge data showed that NCEP-NCAR rainfall data are useful despite important differences between the characteristics in the two data sources. NCEP-NCAR reanalysis data seem to have difficulty in correctly reproducing the strength and orientation of the South Atlantic convergence zone.
\end{abstract}

\section{Introduction}

Several parts of the globe were affected during 1997 and 1998 by both extremes of El Niño-Southern Oscillation (ENSO), with Pacific cold episode (La Niña) conditions prevailing during January and February 1997 and one of the strongest Pacific warm episodes (El Niño) in the historical record during the remainder of 1997 and up to May 1998. La Niña conditions prevailed again during the later part of 1998. The development of these episodes relative to the previous events was discussed by Wang and Weisberg (2000). The index of the Niño3 region $\left(5^{\circ} \mathrm{S}-5^{\circ} \mathrm{N}, 150^{\circ}-90^{\circ} \mathrm{W}\right)$-sea surface temperature, and the Niño-4 region $\left(5^{\circ} \mathrm{S}-5^{\circ} \mathrm{N}, 160^{\circ} \mathrm{E}-150^{\circ} \mathrm{W}\right)-$ zonal wind anomalies, show that the 1997/98 El Niño is the strongest on record (see Fig. 1 of Neelin et al. 2000). During the second half of 1997, SST anomalies across the central and eastern Pacific reached $2^{\circ}-5^{\circ} \mathrm{C}$ above normal. The warming effect of this El Niño was a major factor responsible for the record high global mean surface temperature in 1997. The estimated global mean surface temperature for land and marine areas recorded $0.44^{\circ} \mathrm{C}$ above the $1961-90$ base period mean (WMO 1998).

The influence of ENSO on the rainfall of South America (SA) has been known since the late 1920s (Walker 1928) and has been studied extensively (e.g., Aceituno 1988; Rao and Hada 1990; Ropelewski and Halpert

Corresponding author address: Dr. V. Brahmananda Rao, Instituto Nacional de Pesquisas Espaciais, CP 515, São José dos Campos, SP 12201-970, Brazil.

E-mail:vbrao@cptec.inpe.br
1987, 1989; Pisciottano et al. 1994; and others). These studies generally indicate that in the northern SA rainfall is decreased (increased) during El Niño (La Niña) events and in the southern SA opposite rainfall anomalies occur. Northeast Brazil experiences severe droughts during intense El Niño events and south Brazil and Uruguay experience floods. Rainfall over Chile and the Andean region near the west coast of SA experience close connection with ENSO events. In general, central Chile experiences abundant (less) rainfall during the El Niño (La Niña) events.

In their discussion of climate assessment for 1997 and 1998 Bell and Halpert (1998) and Bell et al. (1999) discussed the global climate anomalies during these years and include only a very brief description of rainfall anomalies over SA. The purpose of the present study therefore is to make a detailed diagnosis of rainfall anomalies over SA during 1997 and 1998. In particular, we propose, 1) to make a comparison between the $\mathrm{Na}$ tional Centers for Environmental Prediction-National Center for Atmospheric Research (NCEP-NCAR) rainfall analysis (Kalnay et al. 1996) over SA and the rain gauge data, and 2) to focus on the potential mechanisms such as water vapor transport and the role of quasistationary waves during 1997 and 1998 using NCEPNCAR reanalysis dataset. These two topics are focused in a two-part study, topic 1 is discussed in the first part and topic 2 in the second part (Rao et al. 2002). It is known that the NCEP-NCAR reanalysis dataset is based on the model assimilation of diverse observations. A study of diagnosis and comparison with rain gauge data 

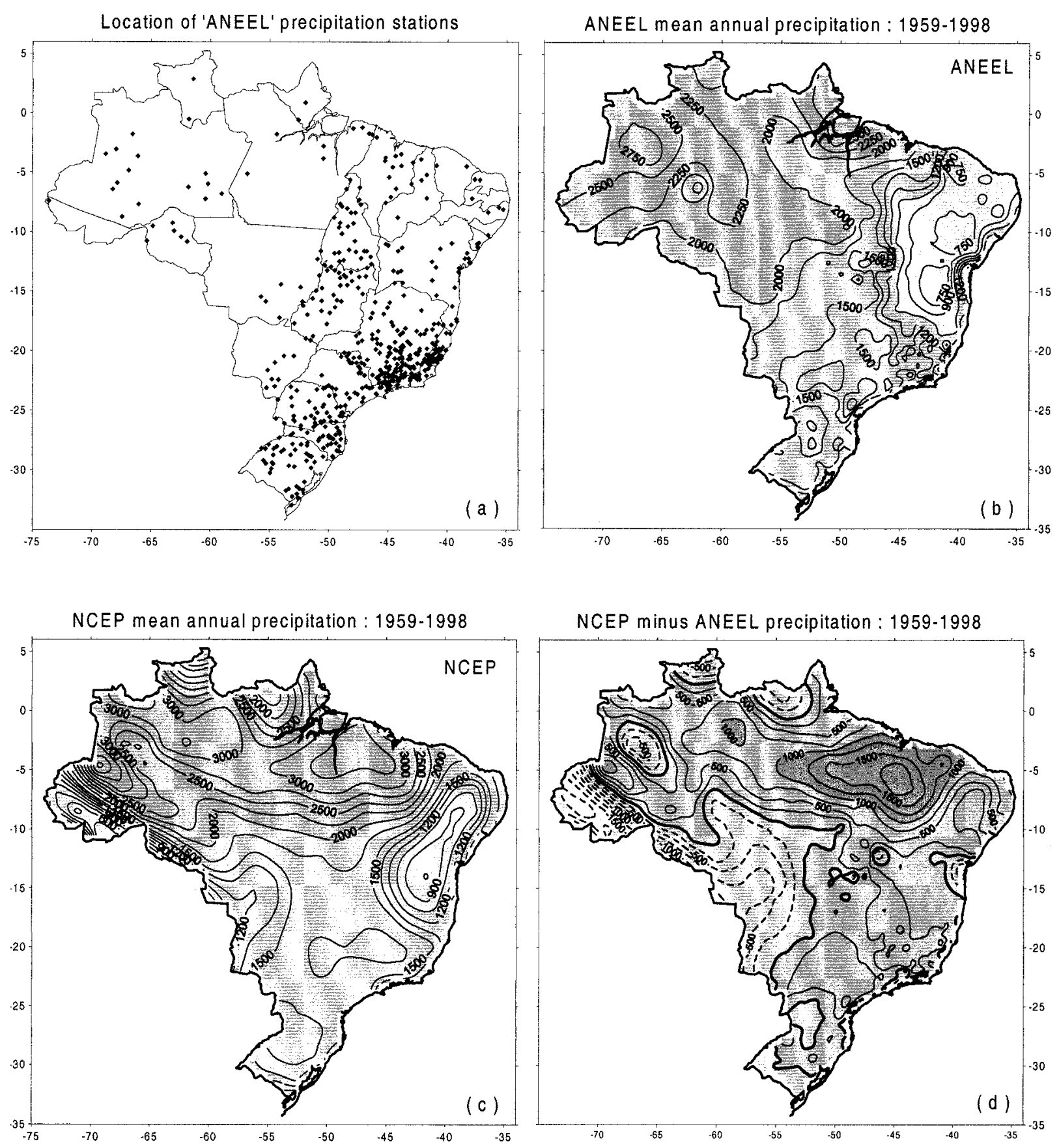

FIG. 1. (a) Station location in ANEEL network of rain gauge stations over Brazil, (b) mean annual rainfall (mm) in ANEEL dataset, (c) mean annual rainfall (mm) in NCEP-NCAR dataset, and (d) the differences between the two datasets. In (b) and (c) rainfall amounts greater than $2000 \mathrm{~mm}$ are shaded. In (d) positive rainfall differences are shaded.

provides an insight into the potential and limitations of this product, which is the objective of Part I.

\section{Data sources}

Rainfall data for the period 1959-98 for Brazil were obtained from Agencia Nacional de Energia Elétrica (ANEEL) of Brazil. These data are available for a rea- sonable number of rain gauge stations (around 450) from about 1959 to date. The data are checked for consistency (deleting unreasonable values from a climatological viewpoint) and are available online at http:// hidroweb.aneel.gov.br. Figure 1a shows the distribution of rain gauge stations used by ANEEL. From Fig. 1a it can be seen that the distribution of rain gauge stations is sparse over the northwest part of Brazil. Although 
Seasonal and annual mean precipitation of the Northwest South America (NCEP : 1959-1998)
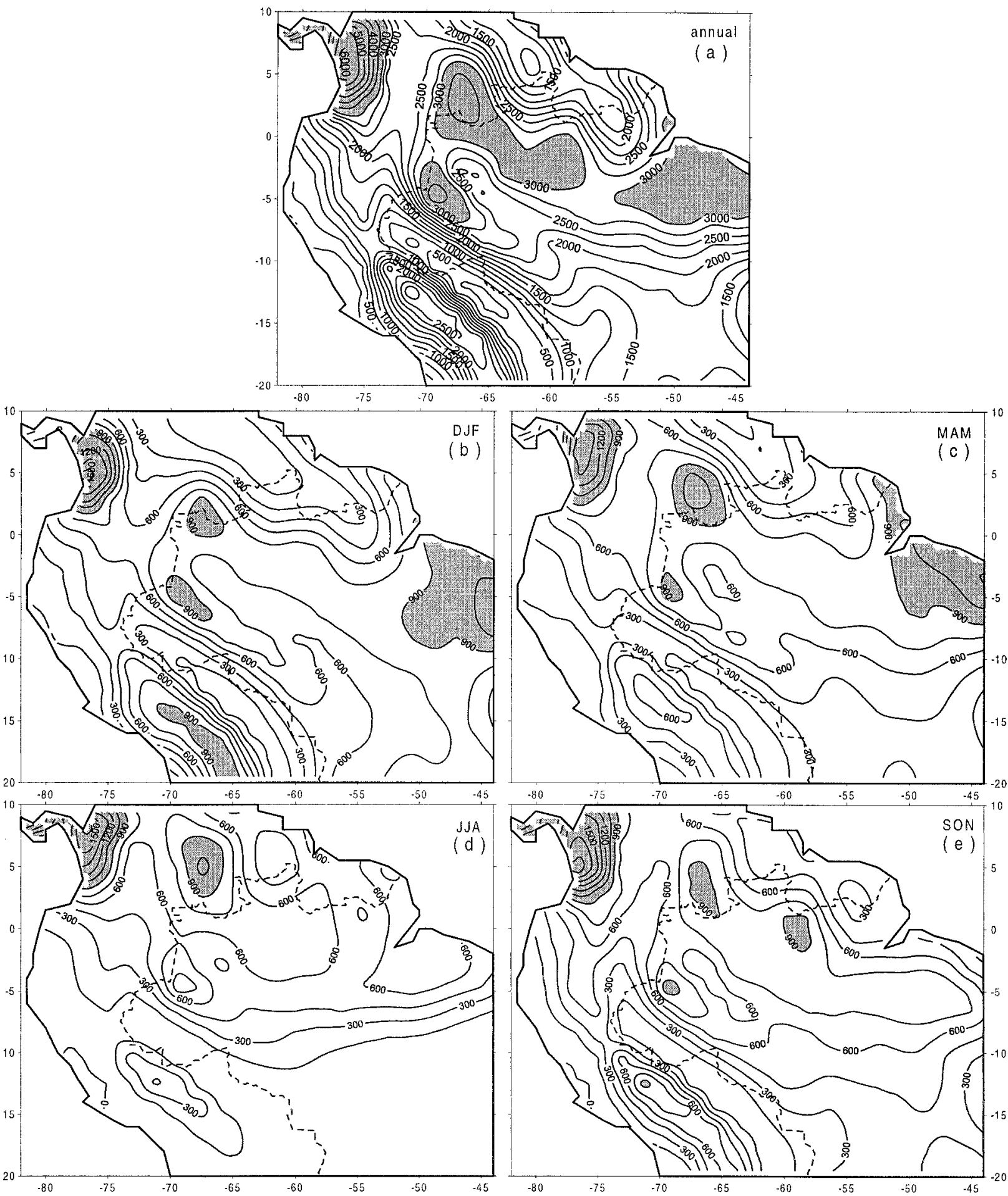

FIG. 2. Rainfall distribution over the northwest part of SA in NCEP-NCAR reanalysis data (mm): (a) annual mean, (b) summer, (c) autumn, (d) winter, and (e) spring. In (a) rainfall amounts greater than $3000 \mathrm{~mm}$ are shaded. In (b)-(d) rainfall amounts greater than $900 \mathrm{~mm}$ are shaded. 


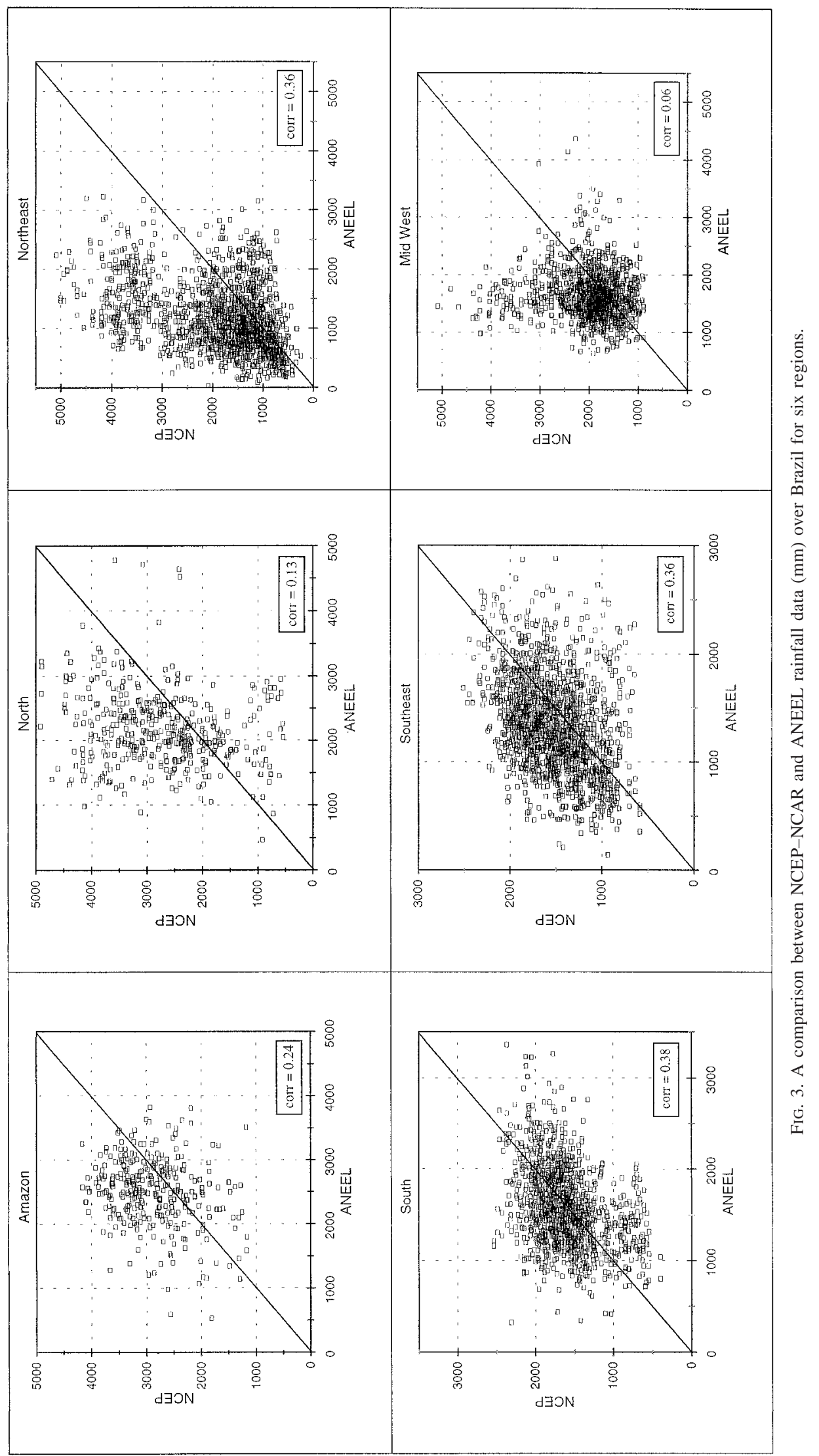


our main interest is to study the rainfall anomalies over SA for the years 1997 and 1998, we propose to compare the characteristics of rainfall in NCEP-NCAR reanalysis and in rain gauge stations for the period 1959-98. The rainfall data over SA were obtained from NCEPNCAR reanalysis.

\section{Diagnosis of Rainfall Anomalies}

\section{a. Characteristics of rainfall over Brazil in NCEP- $N C A R$ reanalysis and rain gauge data}

Since the rain gauge data are available to us only for Brazil we compare the characteristics of rainfall in the two data sources for Brazil. Also we compare the characteristics of rainfall over the northwest part of SA (where the ANEEL data are sparce, Fig. 1a) in NCEPNCAR data with a study by Figueroa and Nobre (1990) using 226 rain gauge stations, which are rather well distributed over this region. Results of Figueroa and Nobre (1990) are summarized in Nobre et al. (1991) and Satyamury et al. (1998). Figures 1b and 1c show the mean annual rainfall for the period 1959-98 in the two data sources. A comparison of the figures shows that there are large quantitative differences, although there are some similarities. In the interior dry region of northeast Brazil, the low rainfall (less than $900 \mathrm{~mm}$ ) is seen in both the data sources. As expected, ANEEL data show more details compared to the NCEP-NCAR $2.5^{\circ}$ resolution. Over southeast and south Brazil the annual rainfall seems to be well reproduced in NCEP-NCAR reanalysis data. Over east Amazonia annual rainfall in NCEP-NCAR reanalysis data is higher and over the northwest part of Brazil, a detailed comparison is not possible because of sparcity of rain gauge stations in ANEEL data in this area. Figure 1d shows the difference between the annual rainfall in the two data sources, which also shows that the NCEP-NCAR analysis reproduces well the rainfall over southeast and south Brazil. While over east Amazonia and northeast Brazil the annual rainfall in NCEP-NCAR reanalysis is higher, that is, there is a positive bias. There is a center of 1750 mm over east Amazonia, and over northeast Brazil the differences are around $500 \mathrm{~mm}$. Over west Amazonia the bias in NCEP-NCAR reanalysis rainfall is negative.

As mentioned earlier, we compare the rainfall characteristics over the northwest part of SA in NCEPNCAR reanalysis data with those given by Figueroa and Nobre (1990). The rainfall distribution over this region in NCEP-NCAR is given in Fig. 2. A comparison of Fig. 2a with Fig. 3C.7 of Satyamurty et al. (1998) shows that the relatively low rainfall of $1500 \mathrm{~mm}$ in the southeast part around $\left(15^{\circ} \mathrm{S}, 45^{\circ} \mathrm{W}\right)$ and about $3000 \mathrm{~mm}$ near the mouth of Amazon River is similar in both figures. Over the northeast of SA, near French Guiana, Surinam, and Guyana the annual rainfall is similar, but the orientation of isohyets is different. The highest observed rainfall of about $5000 \mathrm{~mm}$ over Columbia is shifted
TABLE 1. Number of rain gauge stations, number of data points, and the linear correlation coefficient for six regions of Brazil. The asterisk represents correlation significant at the $99 \%$ level by a twoway $t$ test.

\begin{tabular}{lccc}
\hline \hline & $\begin{array}{c}\text { Number } \\
\text { of stations }\end{array}$ & $\begin{array}{c}\text { Number of } \\
\text { data points }\end{array}$ & $\begin{array}{c}\text { Correlation } \\
\text { coefficient }\end{array}$ \\
\hline Amazon & 14 & 304 & $0.24^{*}$ \\
North & 19 & 416 & 0.13 \\
Northeast & 46 & 1572 & $0.36^{*}$ \\
Southeast & 44 & 1667 & $0.38^{*}$ \\
South & 36 & 1328 & $0.36^{*}$ \\
Midwest & 44 & 1142 & 0.06 \\
\hline
\end{tabular}

somewhat south in NCEP-NCAR data. The high rainfall of $3000 \mathrm{~mm}$ over the central Amazon is devided in two centers in NCEP-NCAR data, while in the rain gauge data only one center is seen. The rainfall over central Peru (of about $4000 \mathrm{~mm}$ ) seems to be underestimated in NCEP-NCAR data. The rainfall distribution over north Chile and Bolivia seems to be similar in both data sources.

To examine the seasonal variation in NCEP-NCAR data, Figs. 2b-e can be compared with Fig. 3C.8 of Satyamurty et al. (1998). The rainfall distribution in summer over north SA including the maximum over Peru is similar in both data sources. The maximum over the south Amazon (of about $900 \mathrm{~mm}$ ) is also well reproduced in NCEP-NCAR data. But similar to what is seen in the mean annual rainfall, there is one more center of high rainfall to the north in NCEP-NCAR data, which is not observed. The tendency to form two centers in this region is seen in all the seasons in NCEP-NCAR data. A center of maximum over central Brazil with northwest to southeast orientation in rain gauge data in summer is not seen in NCEP-NCAR data. This probably shows the difficulty of NCEP-NCAR reanalysis in reproducing the strength and orientation of the South Atlantic convergence zone. A region of high rainfall over Peru in all seasons is also seen in NCEP-NCAR data, but similar to the annual distribution is shifted to south. The high rainfall over northeast Brazil in March, April, and May in the rain gauge data is also seen in NCEPNCAR data.

To explore further the limitations and potential of NCEP-NCAR reanalysis precipitation data over Brazil, Fig. 3 was prepared. This figure shows the rainfall in NCEP-NCAR reanalysis plotted against ANEEL data for six regions in Brazil: Amazon, north, northeast, south, southeast, and midwest. The number of rain gauge stations and number of data points in Fig. 3 are shown in Table 1. The values of the linear correlation coefficients (cc) are shown in the lower-right-hand corner of Fig. 3 and also in the last column of Table 1. For north and northeast Brazil, NCEP-NCAR data tend to overestimate rainfall; the tendency for this is particularly high for the northeast region. A similar tendency is also seen for the midwest region and the cc is very low. Considering the Amazon region as a whole the $\mathrm{cc}$ is 


\section{PERCENTAGE OF SEASONAL PRECIPITATION}

NCEP: 1959-1998
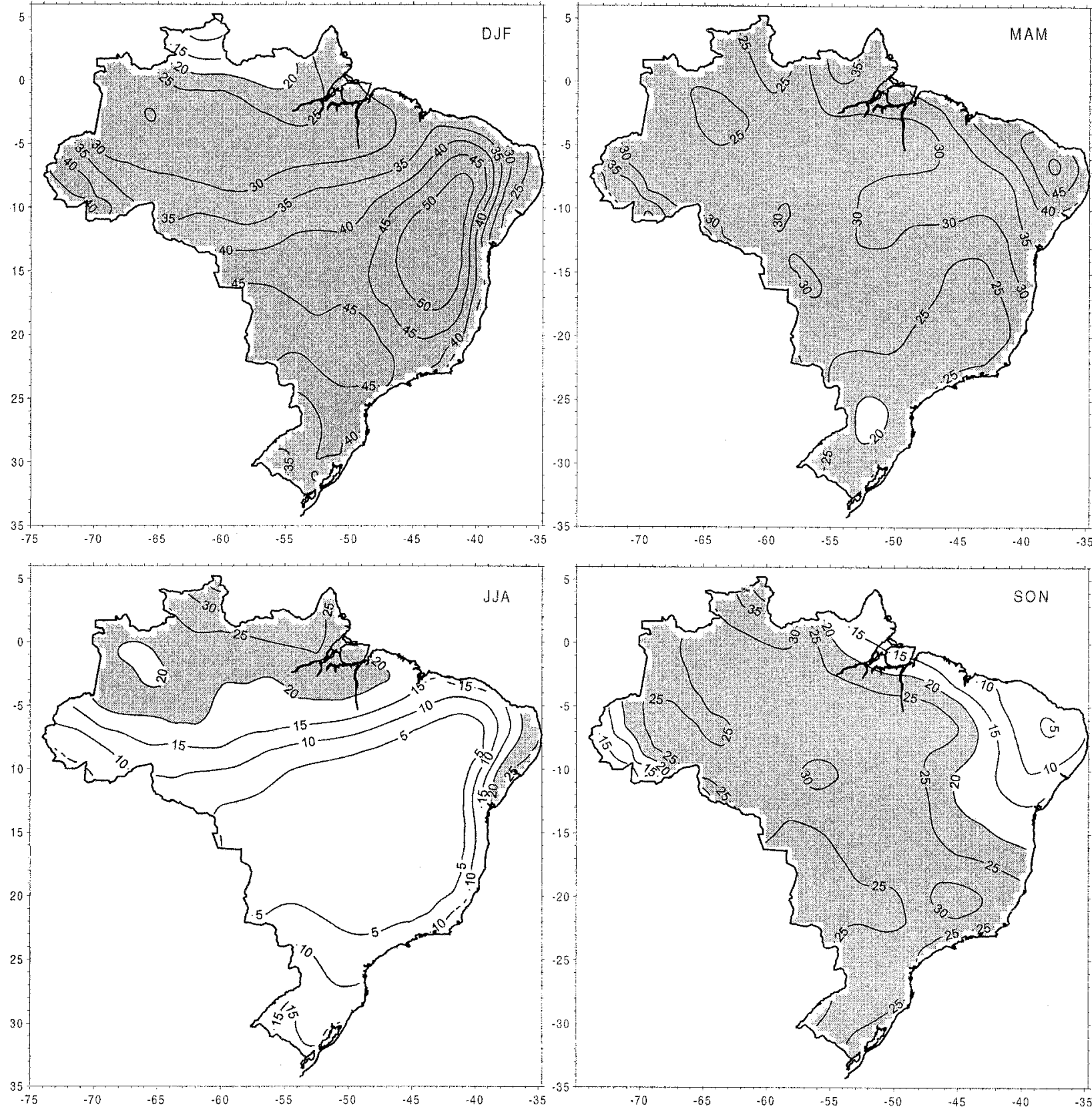

FIG. 4. Percentage of each 3-month rainfall period to the annual mean (NCEP-NCAR). Areas with percentages greater than $20 \%$ are shaded.

also low. For the south and southeast, the ccs are highly significant (at 99\%) showing the utility of NCEPNCAR reanalysis rainfall data for these two regions. Even for northeast Brazil, although NCEP-NCAR reanalysis data overestimates the rainfall, it is still useful in view of the sparce distribution of rain gauge stations. For other regions, the validity of NCEP-NCAR rainfall data is questionable in view of the low correlation.
To examine the annual cycle of rainfall over Brazil Figs. 4 and 5 were prepared. These figures show the percentage of each 3-month rainfall period to the annual rainfall in both the data sources. A comparison of these two figures shows that about $50 \%$ of annual rainfall in summer [December-January-February (DJF)] over the central parts of Brazil is reproduced well in reanalysis data, although the contour of $50 \%$ is somewhat shifted 


\section{PERCENTAGE OF SEASONAL PRECIPITATION}

ANEEL : 1959-1998
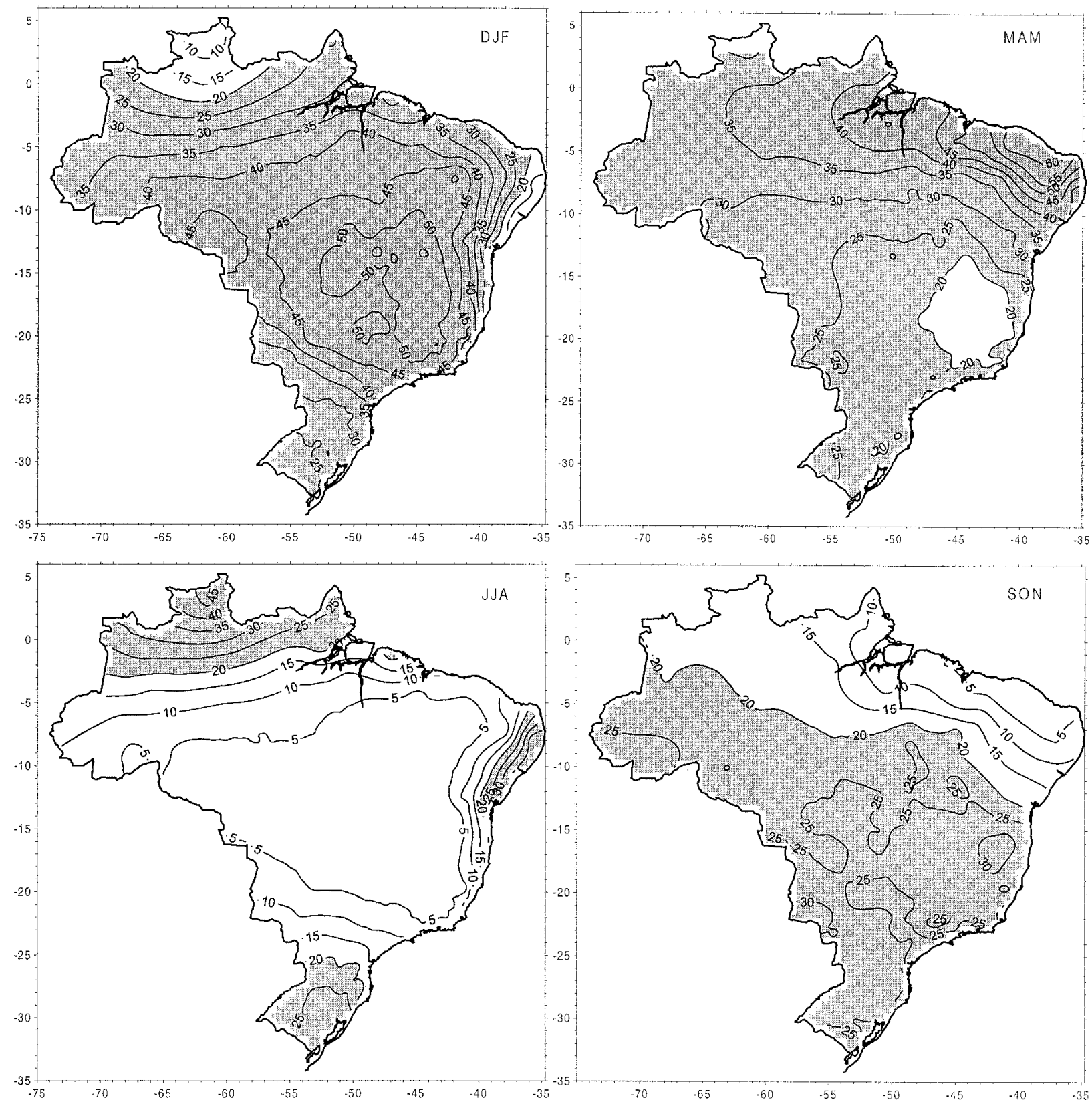

FIG. 5. Same as Fig. 4 but for ANEEL data.

eastward compared to ANEEL data. The principal rainy season in MAM over northeast Brazil, although shifted eastward, is qualitatively reproduced well in reanalysis data. This eastward shift is similar to the positive bias over northeast Brazil in NCEP-NCAR reanalysis precipitation noted earlier. The main dry period (about 5\% of annual rainfall) in JJA over most of Brazil is similar in both data sources. Higher rainfall over coastal northeast Brazil in JJA is also shown in reanalysis data. The shift of the principal rainy region to the northwest in
JJA is also seen in both data sources. The distribution of the isolines of percentage in SON is similar in both the data sources.

\section{b. Rainfall over SA during 1997 and 1998}

Figure 6 shows the observed annual rainfall (ANEEL) over Brazil and their anomalies from the long-term mean (1959-98). It can be seen from this figure that the rainfall was higher (positive anomalies) over the south- 
Mean annual precipitation (ANEEL)
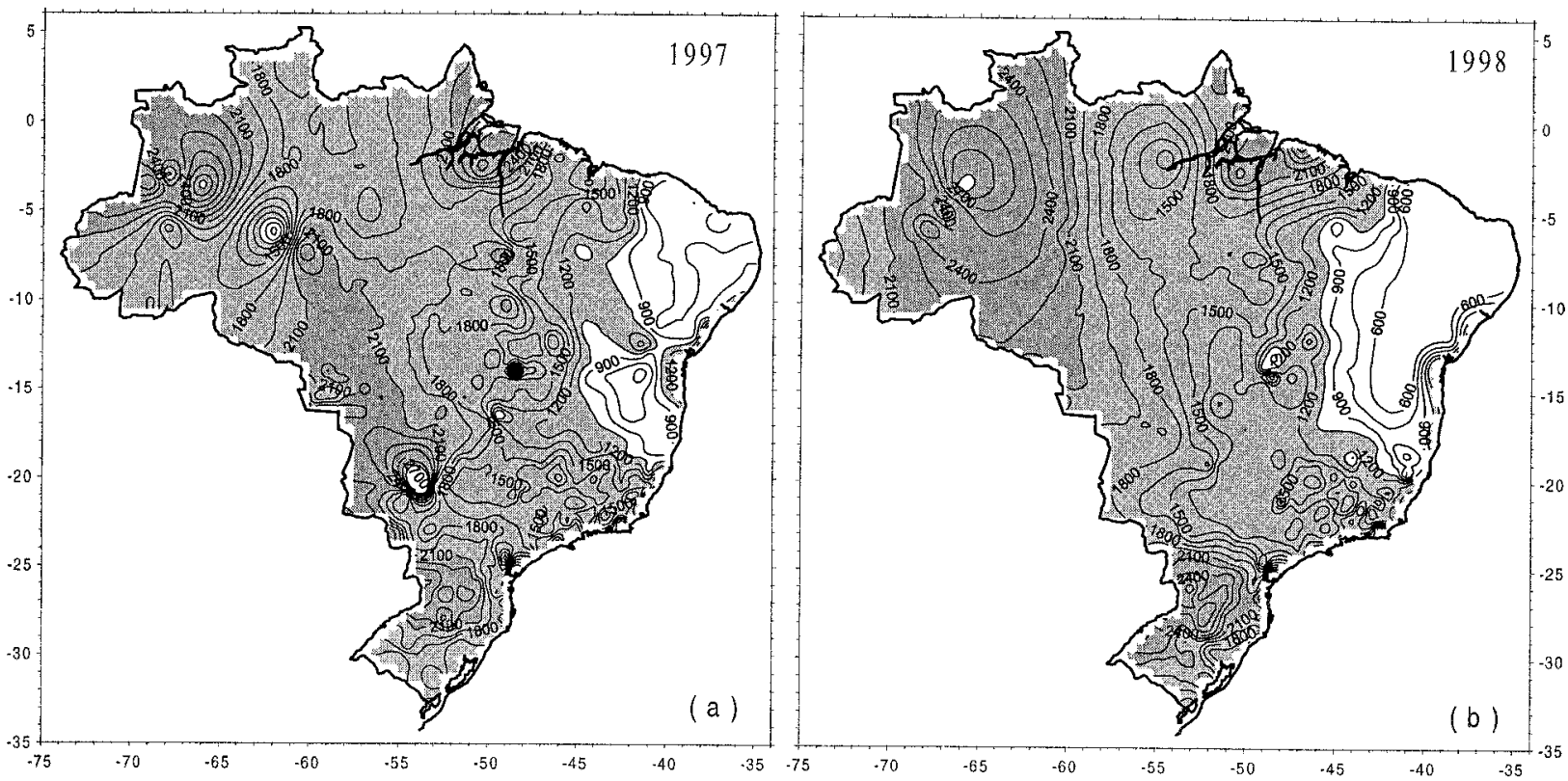

Anomaly of mean annual precipitation (ANEEL)
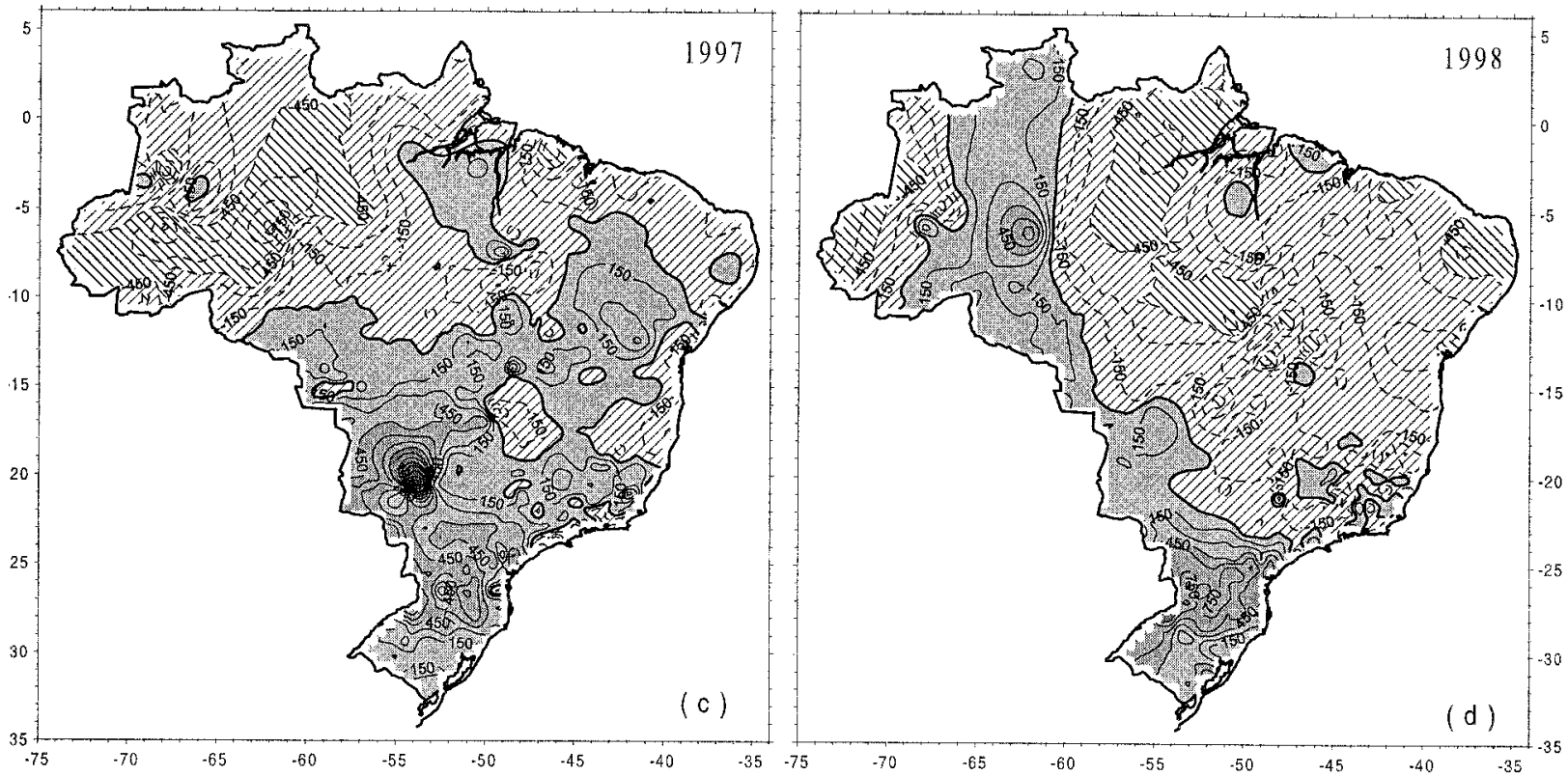

FIG. 6. Mean annual rainfall (mm) for (a) 1997 and (b) 1998 (ANEEL). Anomaly of (c) 1997 and (d) 1998 annual rainfall (mm) with respect to the normal (mean of 1959-98). In (a) and (b) rainfall amounts greater than $1050 \mathrm{~mm}$ are shaded. In (c) and (d) positive anomalies are shaded and negative anomalies have diagonal hatching.

eastern parts of Brazil in 1997 and the rainfall was lower (negative anomalies) over the eastern parts of Brazil in 1998. Over northeast Brazil, negative rainfall anomalies in 1998 were between 150 and $450 \mathrm{~mm}$. Over south Brazil, the positive anomalies in 1998 were much higher than in 1997. These are some of the well-known features associated with El Niño and La Niña events (Aceituno 1988; Ropelewski and Halpert 1987; Rao and Hada
1990). Over the western parts of Brazil, because of the sparcity of the distribution of rain gauge stations (Fig. 1), a detailed analysis could not be made. Some rain gauges over the southwest part of Brazil indicated higher rainfall in 1997.

Figure 7 shows the seasonwise separation of difference in precipitation in NCEP-NCAR reanalysis data between 1997 and 1998. Because of the aforementioned 

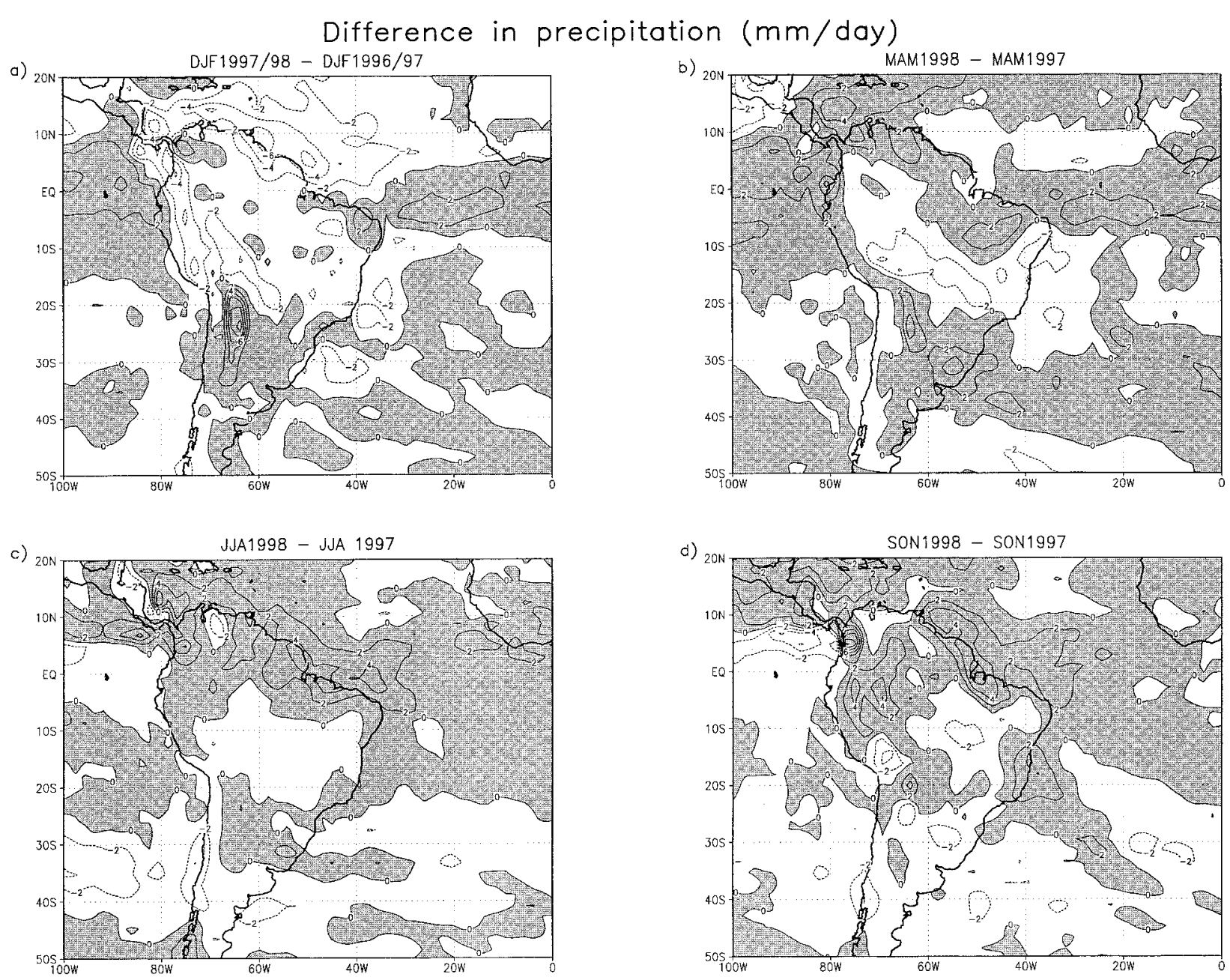

FIG. 7. Difference in precipitation $\left(\mathrm{mm} \mathrm{day}^{-1}\right)$ for different seasons between 1998 and 1997 (NCEP-NCAR). Positive differences are shaded.

bias in the reanalysis precipitation data, we preferred to discuss the differences such that the systematic bias cancels and the differences are more reliable than the individual values. During the summer season (Fig. 7a) positive values with a maximum of $6 \mathrm{~mm}$ day $^{-1}$ are seen over Chile, Bolivia, north Argentina, and south Brazil (southwest SA); and negative anomalies (more than $2 \mathrm{~mm} \mathrm{day}^{-1}$ ) are seen in the northwestern parts over Equador, Columbia, and Panama. Negative anomalies are also seen over Venezuela and the east. Over the eastern equatorial Pacific and equatorial Atlantic and the adjoining SA continent, positive anomalies are seen. Positive (negative) values indicate higher (lower) rainfall during the summer of 1997/98 (1996/97). Positive values over the equatorial Atlantic indicate that the convective precipiatation associated with the intertropical convergence zone (ITCZ) was higher during the El Niño summer of 1997/98. While positive values over the equatorial Pacific indicate higher convection associated with positive anomalies of SST associated with El Niño.

During the autumn (MAM) season, the negative anomalies over northwest SA and Central America were replaced by positive anomalies. Over the equatorial eastern Pacific and equatorial Atlantic positive anomalies continued; over northeast Brazil negative anomalies (of around $2 \mathrm{~mm} \mathrm{day}^{-1}$ ) are observed indicating a drier rainy season in MAM 1998. In MAM 1998 northeast Brazil experienced a severe drought. During this season in northeast Brazil, the rainfall anomalies (from the 1959-98 mean) are around $-300 \mathrm{~mm}$ (figure not shown). This is due to a northward position of ITCZ in MAM compared to MAM 1997. Hastenrath and Heller (1977) suggested that droughts in northeast Brazil are associated with a northward (compared to normal) shift of ITCZ. Over north Argentina, south Brazil, Paraguay, and Uruguay positive values indicate higher rainfall during MAM 1998. During the winter (JJA) of 1998, the rainfall was higher (positive values) over north SA and the adjoining Atlantic Ocean. During the spring of 1998, the rainfall over the eastern equatorial Pacific was lower indicating a reduction of convection, probably due to 
the lowering of SST there. This is consistent with the establishment of La Niña by spring 1998.

\section{Conclusions}

In the present two-part study we made an attempt to diagnose rainfall over SA during the strongest El Niño event on record namely that of 1997/98. In this part we evaluated the potential and limitations of NCEP-NCAR rainfall analysis over SA using $50 \mathrm{yr}$ of data. It is found that NCEP-NCAR rainfall is overestimated over northeast Brazil in comparison with rain gauge station data. A detailed comparison between NCEP-NCAR rainfall data over northwest SA with rain gauge data of Figueroa and Nobre (1990) showed that NCEP-NCAR rainfall data are useful despite important differences between the characteristics in the two data sources. NCEPNCAR reanalysis has difficulty in reproducing correctly the strength and orientation of the South Atlantic convergence zone. Over southeast and south Brazil the cc between the two rainfall data is highly significant showing the utility of NCEP-NCAR rainfall analysis for these regions. Over the Amazon, north and midwest regions of Brazil NCEP-NCAR rainfall data are of questionable quality. However, the seasonal distribution of rainfall over Brazil in NCEP-NCAR data seems to be reasonable, so that the principal rainfall seasons are reproduced well.

Acknowledgments. We are grateful to Prof. S. Hastenrath for his constructive criticism. NCEP-NCAR reanalysis data were provided by the NOAA-CIRES Climate Diagnostics Center, Boulder, Colorado, from their site online at http://www.cdc.noaa.gov/. Rain gauge data from Brazil were obtained from ANEEL (Agência Nacional de Energia Elétrica).

\section{REFERENCES}

Aceituno, P., 1988: On the functioning of the Southern Oscillation in the South America sector. Part I: Surface climate. Mon. Wea. Rev., 116, 505-524.

Bell, G. D., and M. S. Halpert, 1998: Climate assessment for 1997. Bull. Amer. Meteor. Soc., 79, S1-S50.

_ - M. S. Halpert, C. F. Ropelewski, V. E. Kousky, A. V. Douglas, R. C. Schnell, and M. E. Gelman, 1999: Climate assessment for 1998. Bull. Amer. Meteor. Soc., 80, S1-S48.

Figueroa, S. N., and C. A. Nobre, 1990: Precipitation distribution over central and western tropical South America. Climanálise, 5, 36-40.

Hastenrath, S., and L. Heller, 1977: Dynamics of climatic hazards in Northeast Brazil. Quart. J. Roy. Meteor. Soc., 103, 77-92.

Kalnay, E., and Coauthors, 1996: The NCEP/NCAR 40-Year Reanalysis Project. Bull. Amer. Meteor. Soc., 77, 437-471.

Neelin, J. D., F.-F. Jin, and H.-H. Syu, 2000: Variations in ENSO phase locking. J. Climate, 13, 2570-2590.

Nobre, C. A., P. J. Sellers, and J. Shukla, 1991: Amazonian deforestation and regional climate change. J. Climate, 4, 957-987.

Pisciottano, G. F., A. F. Diaz, G. Cazes, and C. R. Mechoso, 1994 El Niño-Southern Oscillation impact on rainfall in Uruguay. $J$. Climate, 7, 1286-1302.

Rao, V. B., and K. Hada, 1990: Characteristics of rainfall over Brazil: Annual variations and connections with the Southern Oscillation. Theor. Appl. Climatol., 42, 81-91.

_ _ S. R. Chapa, J. P. R. Fernandez, and S. H. Franchito, 2002: A diagnosis of rainfall over South America during the 1997/98 El Niño event. Part II: Roles of water vapor transport and stationary waves. J. Climate, 15, 512-521.

Ropelewski, C., and M. S. Halpert, 1987: Global and regional scale precipitation patterns associated with the El Niño/Southern Oscillation. Mon. Wea. Rev., 115, 1606-1626.

$\ldots$, and - 1989: Precipitation patterns associated with the high index phase of the Southern Oscillation. J. Climate, 2, 268-284.

Satyamurty, P., C. A. Nobre, and P. L. Silva Dias, 1998: South America. Meteorology of the Southern Hemisphere, Meteor. Monogr., No. 49, Amer. Meteor. Soc., 119-139.

Walker, G. T., 1928: Ceará (Brazil) famines and the general air movement. Beitr. Phys. Frain. Atmos., 14, 88.

Wang, C., and R. H. Weisberg, 2000: The 1997-98 El Niño evolution relative to previous El Niño events. J. Climate, 13, 488-501.

WMO, 1998: WMO statement on the status of the global climate in 1997. WMO No. 877,10 pp. 